\title{
Pattern of partial reinforcement and resistance to extinction in the immature rat
}

\author{
WILLIAM A. ROBERTS
}

VASSAR COLLEGE

Three groups of immature rats were given partially reinforced training, one group with an alternating pattern, another with a Gellermann pattern, and a third with an extended pattem, while a fourth group was consistently reinforced. The altemating pattem was clearly discriminated in acquisition. In extinction, the Consistent Group extinguished faster than the partially reinforced groups, and the Altemating Group extinguished faster than the Gellermann and Extended groups. These results are in agreement with findings for the adult rat, and only the failure to find a difference in resistance to extinction between Gellermann and Extended groups is discrepant with adult rat results.

A recent investigation of learning in the immature rat revealed progressive improvement in habit-reversal and maximizing in probability-learning, phenomena well known in the adult rat (Roberts, 1966). These results suggest the interesting hypothesis that the immature rat may possess the same learning abilities as the adult rat. A complete exploration of the hypothesis requires that a variety of learning phenomena, well established with the adult rat, be studied in the immature rat. Since no studies of partial reinforcement have been made in the immature rat, the effects of partial and consistent reinforcement on resistance to extinction were examined in this experiment. This experiment was designed to answer two questions: (1) Does the partial reinforcement effect (PRE) appear in the immature rat? (2) Do different patterns of partial reinforcement produce the same differences in acquisition and extinction in the immature rat as they do in the adult rat?

In the adult rat, an alternating pattern of partial reinforcement eventually leads to patterned responding in which the animal responds more rapidly following nonreinforced trials than following reinforced trials while an irregular, Gellermann pattern leads to equally rapid responding after reinforced and nonreinforced trials. In extinction, animals trained with an alternating pattern show less resistance to extinction than those trained with a Gellermann pattern (Tyler et al, 1953). While the Gellerman pattern allows only three consecutive nonreinforcements to occur, a third pattern, the extended pattern, provides much longer runs of nonreinforced trials. It has been found that in early extinction, both Gellermann and extended animals show marked resistance to extinction. However, in the later stages of extinction, Gellermann animals extinguish while extended animals maintain a high resistance to extinction (Gonzalez \& Bitterman, 1964). In this experiment, Alternating, Gellermann, Extended, and Con- sistent groups of immature rats were studied in acquisition and extinction.

Method

The apparatus consisted of a starting box ( $5 \times 9 \times 6$ in.), a runway ( $5 \times 93 \times 6$ in.), and a goal box ( $7 \times$ $13.5 \times 6$ in.), all made of wood and painted gray with hinged Plexiglas tops. The goal box was placed at a right angle to the end of the runway and was entered by a right turn. A guillotine door separated the starting box and runway. When this door was raised, a microswitch, mounted below the door, was opened starting a clock. When Sbroke a beam of red light passing across the runway $84 \mathrm{in}$. from the starting box door, the clock stopped. Times were recorded in .01 sec. and transformed to logs. A horizontally sliding Plexiglas door, located 24.5 in. before the goal box entrance, was closed after $S$ entered the goal box to prevent retracing. The S's reward was contained in a glass dish placed at the rear of the goal box.

The Ss were 32 male and female immature albino rats of the Wistar strain. They were run 15-18 hr. food deprived each day and were allowed to eat hard pellets ad lib for $5 \mathrm{hr}$. $1 \mathrm{hr}$. after each day's trials. The Ss were 22-25 days old on the first day of the experiment.

Each $S$ was given 20 massed trials per day in both acquisition and extinction. On the first day of the experiment, all Ss were consistently reinforced. On the basis of mean time scores on the first day, the Ss were matched into four equivalent groups of eight Ss each. Three of the groups were then trained for nine days on $50 \%$ partial reinforcement. The Alternating Group was reinforced on odd trials, and the Gellermann Group was reinforced according to selectedGellermann orders with the first trial of each day being reinforced. The schedule

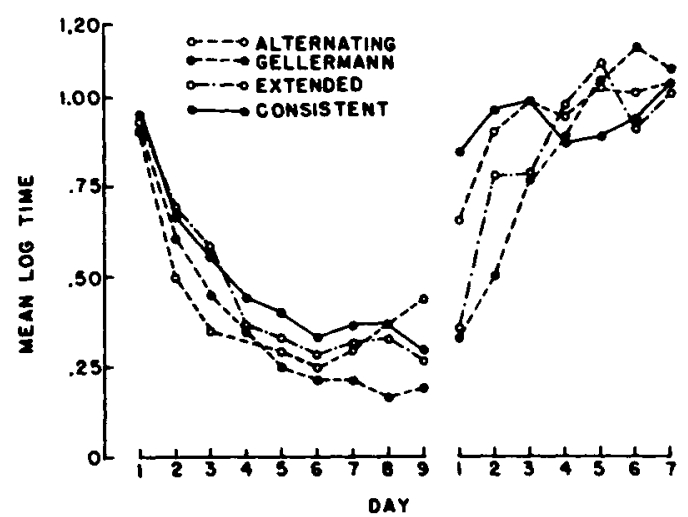

Fig. 1. Acquisition and extinction curves for four groups. 
for the Extended Group was arranged to provide for long runs of nonreinforced trials; on days 1-9 of partial reinforcement, the longest run on each day was $3,6,8$, $7,8,9,9,8$, and 5 , respectively. These runs were continuous between days 4 and 5 and days 7 and 8 , making for runs of 15 and 17 nonreinforcements between days. The Consistent Group received 20 reinforced trials each day for nine days. On reinforced trials, $S$ was allowed to eat wet mash in the goal box for $10 \mathrm{sec}$. On nonreinforced trials, the food dish was removed from the goal box, and $S$ remained in the empty goal box for $10 \mathrm{sec}$. The intertrial interval was approximately $20 \mathrm{sec}$. Following the final day of acquisition, animals were extinguished for seven days. There were 20 nonreinforced trials each day with the procedure on each trial being the same as on nonreinforced trials during acquisition. If $S$ did not reach the end of the runway within $90 \mathrm{sec}$. on an extinction trial, it was removed from the apparatus and given a score of $90 \mathrm{sec}$.

\section{Results and Discussion}

One animal in the Extended Group died in the course of the experiment, and the data presented for this group are based on an $\mathrm{N}$ of 7 . In Fig. 1, it can be seen that the acquisition curves for all four groups decline in a negatively accelerated fashion reaching asymptote on days 6-9. Analysis of variance shows a nonsignificant Groups effect $(F=2.55, d f=3 / 27)$, a significant Days effect $(F=78.74, d f=8 / 216)$, and a significant Groups by Days interaction $(F=1.59, d f=24 / 216)$. This interaction is largely due to the terminal rise in the Alternating curve, reflecting the discrimination of the alternating pattern. This is more clearly seen in Fig. 2 where performance on day 9 is plotted for Alternating and Gellermann groups. While the Alternating curve rises sharply on nonreinforced trials, the Gellermann curve is relatively flat. It appears that the immature rat is quite capable of discriminating an alternating pattern just as the adult rat is.

Extinction curves are also shown in Fig. 1. It appears that the Consistent and Alternating groups extinguish more rapidly than the Gellermann and Extended groups, and this is verified by a significant Groups by Days interaction $(F=2.69, d f=18 / 162)$. The Days effect is

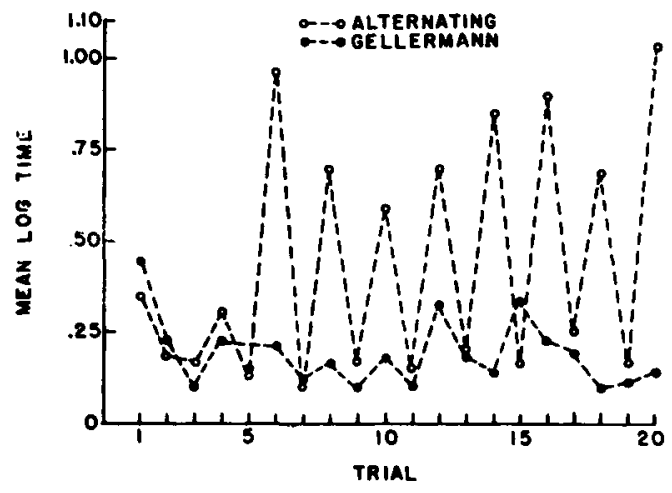

Fig. 2. Within-day performance on Day 9 of acquisition.

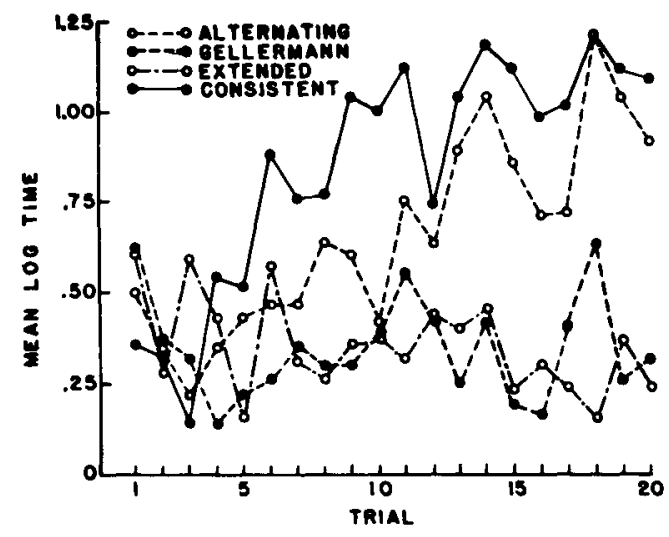

Fig. 3. Within-day performance on Day 1 of extinction.

also significant ( $F=24.65$, $d f=6 / 162$ ), but the Groups effect does not approach significance $(F<1)$. In Fig. 3 , performance over the 20 trials of the first day of extinction is plotted. The PRE is clearly apparent here, the Consistent Group extinguishing faster than any of the partial reinforcement groups. The Alternating curve rises above the Gellermann and Extended curves which remain essentially flat throughout the 20 trials. Analysis of variance on these curves provides a significantGroups effect ( $F=11.57, d f=3 / 27$ ), a significant Trials effect $(F=4.14, d f=19 / 513)$, and a significantGroups by Trials interaction $(F=2.11, d f=57 / 513)$. $T$-tests show that all differences between individual groups are significant at the .05 level except that between the Alternating and Consistent groups $(t=1.73, \mathrm{df}=14)$ and that between the Gellermann and Extended groups $(t<1)$.

The immature rat shows both the PRE and greater resistance to extinction following Gellermann training than following alternating training. These results are in line with those found for the adult rat and further support the hypothesis that the immature rat is functionally equivalent to the adult rat. Only the failure of the Extended Group to show greater resistance to extinction than the Gellermann Group is discrepant with adult rat findings. While this result could be the product of an ontogenetic difference in the way extended training affects immature and adult rats, it is also possible that a greater number of acquisition trials would bring out the Gellerman-Extended difference in the immature rat. This possibility is supported by the fact that all experiments with the adult rat which have shown this effect have involved more acquisition trials than were used here.

\section{References}

Gonzal es, R. C., \& Bitterman, M. E. Resistance to extinction in the rat as a function of percentage and distribution of reinforcement. J. comp. physiol. Psychol., 1964, 58, 258-263.

Roberts, W. A. Learning and motivation in the immature rat. Amer. J. Psychol., 1966, 79, 3-23.

Tyler, W. D., Wortz, E. C., \& Bitterman, M. E. The effect of random and alternating partial reinforcement on resistance to extinction in the rat. Amer. J. Psychol., 1953, 66, 57-65. 